\title{
PHASE BOUNDARY CORRELATION IN NATURAL SYSTEMS: AN EXAMPLE FOR IRON-OXIDE TRANSFORMATIONS
}

\author{
Barbosa, P. F. ${ }^{1, *}$; Lagoeiro, L. ${ }^{2}$ \\ ${ }^{1}$ Center of Microscopy. Federal University of Minas Gerais, Belo Horizonte, MG, Brazil \\ ${ }^{2}$ Microlab. Department of Geology, Federal University of Ouro Preto, Ouro Preto, MG, Brazil \\ *paolafeba@yahoo.com.br
}

\begin{abstract}
If two phases areii associated by a reversible reaction of phase transformation, it is possible to stablish a crystallographic relationship of symmetry. The EBSD (electron backscattering diffraction) emerges as a reliable technique to study phase transformation, mainly in mineralogical systems. The sample preparation is relatively standard and the analyses are faster based on the amount of generated data. To test EBSD as a tool to predict the crystallographic parallelism in a mineralogical system, one sample of iron-formation from Iron Quadrangle, MG, Brazil was chosen. We selected the lattice correlation boundary component (LC) in EBSD system from Oxford-HKL to display phase boundaries. In this component, the frequency of the angle between these two chosen planes/directions is calculated. In our system, the main transformation occurs between magnetite $\left(\mathrm{Fe}_{3} \mathrm{O}_{4}-\mathrm{Fd} 3 \mathrm{~m}\right)$ and hematite $\left(\mathrm{Fe}_{2} \mathrm{O}_{3}-\mathrm{R}-3 \mathrm{c}\right)$. We choose the highest symmetry planes of both minerals. According to the frequency histograms, it is possible to observe that the highest coincidence occurs to the pair hematite vs magnetite: 0001 vs111 and 10-10vs110. Both correlations are predicted in previous works corroborating the importance of LC component in crystallographic studies of mineral transformation.
\end{abstract}

